\title{
1. An introduction to Contextual Heterogeneity in Entrepreneurship Research
}

\author{
Eddy Laveren, Cyrine Ben-Hafaïedh, \\ Agnieszka Kurczewska and Yi Dragon Jiang
}

\section{INTRODUCING THE THEME OF THE BOOK}

\section{Importance of Contextual Heterogeneity in Entrepreneurship Research}

In management research, context primarily refers to circumstances, conditions, or environments that are external to the respective phenomenon and enable or constrain it (Welter, 2011). Context also matters for entrepreneurship, because it is influenced by cultural, political, and economic environments, thus relating to context in research helps to explain cross-national and cross-cultural differences in themes and topics (Welter and Lasch, 2008; Baker and Welter, 2018). Such a way of conducting research influences not only the way data are interpreted, but also the whole research process, starting from formulating assumptions, deriving research questions or hypotheses, to making observations from data analysis.

The call for more contextualized studies in entrepreneurship has been already addressed in entrepreneurship literature. Ucbasaran et al. (2001) suggest that entrepreneurship research needs additional studies that would explore entrepreneurial behaviour across differing organizational contexts and under differing external environmental conditions. In a similar vein, Welter (2011, pp. 165-166) argues that

there is growing recognition in entrepreneurship research that economic behavior can be better understood within its historical, temporal, institutional, spatial, and social contexts, as these contexts provide individuals with opportunities and set boundaries for their actions ... context is important for understanding when, how, and why entrepreneurship happens and who becomes involved. 
Zahra and Wright (2011) recommend that more research should address the heterogeneity of the contexts in which entrepreneurial activities take place. The need for contextual research was also acknowledged by Blackburn et al. (2015), who mention that it is important to understand the heterogeneity within the contexts and the continuous changes in the environments in which entrepreneurship is researched.

A recognition of the importance of context in research goes hand in hand with one of the interests of entrepreneurship researchers. Landström and Harirchi (2019) show that contextual considerations in the research are regarded as interesting among a large group of entrepreneurship scholars. Therefore, it seems relevant to strengthen the contextual heterogeneity of entrepreneurship research and continue a discussion on its meaning for the quality of the future research.

\section{What are the Key Dimensions of Contextual Heterogeneity?}

Context is a multi-dimensional concept and its different dimensions are also interrelated. Zahra and Wright (2011, p. 75) identify four dimensions of context: temporal, institutional, social and spatial. Combining Zahra et al. (2014) and Welter (2011) it is possible to offer a more refined categorization comprising eight dimensions: (1) temporal, (2) historical, (3) institutional, (4) industry and market, (5) social, (6) organizational, (7) spatial, and (8) ownership and governance.

First, the temporal context concerns the study of time and its implications for entrepreneurial phenomena. It involves consideration of the different life-cycle phases of a venture, from the opportunity recognition phase through to maturity and decline. The temporal dimension has implications for the development of leadership in companies, and how entrepreneurs and companies learn and become sustainable ventures.

Second, entrepreneurship scholars have started to systematically introduce historical considerations and historical methods into entrepreneurship research (Landstöm and Lohrke, 2010). It is also worth remembering that the understanding of entrepreneurship is a reflection of the times and thus the level of knowledge of those days. Welter (2011) draws attention to historical contexts, by referring to historical influences on the nature and extent of today's entrepreneurship.

Third, the institutional dimension concerns the effect of different institutional contexts, not only the characteristics of the external environment in which ventures emerge and compete but also the role of national and regional institutions that may influence the extent and nature of entrepreneurship. For example, entrepreneurship scholars study the institutional contexts of women's entrepreneurship and immigrant entrepreneurship. 
Fourth, industries and markets play a major role in determining differences in economic opportunities between countries. Industries involve contexts that vary in the opportunities they offer as well as the intensity of their competitive forces (Porter, 1980). Wright et al. (2007) point out the need to consider the nature of the industry context before drawing conclusions about (international) strategies of entrepreneurs. Industry and market influence the strategies that entrepreneurs adopt and therefore knowing their context helps to understand entrepreneurial decisions and directions of companies' development.

Fifth, the social dimension concerns the relationships between the various parties that influence the emergence and the development of ventures. Networks are a key source of information, resources, and access to markets (Stuart and Sorenson, 2007). Networks support the creation, growth, and success of new ventures. Networks have an important role in the development and functioning of entrepreneurial ecosystems.

Sixth, another dimension of context covers the complementarities and substitutions among different organizational forms. Some organizational contexts may facilitate entrepreneurship. Mismatches between organizational context and the demands of a commercialization process can hinder entrepreneurial activities. Family firms, seen as a particular organizational form, are heterogeneous and differences may also influence the extent to which entrepreneurial activities are encouraged.

Seventh, entrepreneurship researchers have also studied the effect of the spatial dimension of context by highlighting the role of geography and location on where new ventures develop and grow, the relationships they establish with their key stakeholders, and their participation in different networks as well as where and how they assemble resources (Zahra et al., 2014).

Finally, ownership and its different effects throughout the entrepreneurial process represent another dimension of context. The different ownership structures involving varying degrees of alignment between ownership and control give rise to contextual differences that may affect entrepreneurial behaviour (Zahra et al., 2014). Ownership differences interact with other dimensions of context to influence the outcome of entrepreneurial behaviour. Also, the nature of governance and in particular the role and compositions of the Board of Directors will influence the strategy development of entrepreneurs.

The richness and the heterogeneity of context in entrepreneurship incite scholars to see the investigated phenomenon from different perspectives, which subsequently capture the scholars' imagination and direct them towards a deeper understanding of how context influences our method and reasoning. 


\section{How to Incorporate Contextual Heterogeneity in Research}

Awareness of the significance of the context in interpreting entrepreneurship and incorporating contextual heterogeneity improve the quality and relevance of entrepreneurship research. However, as Zahra and Wright (2011) argue, contextualized research practices also change our research approach and methods. Instead of controlling for contextual variables, as is common in quantitative research, context becomes part of the story being told. Context specific aspects can give a unique meaning to events and issues and therefore better understanding of entrepreneurship phenomenon. More attention should be given to longitudinal process studies as well as different kinds of qualitative research methods such as interviews, case-based research, storytelling, narratives, and discourse analysis

\section{INTRODUCING THE CHAPTERS}

Following this introduction the volume presents eight chapters with examples of excellent research demonstrating the importance and influence of contextual heterogeneity in the field of entrepreneurship research.

In Chapter 2, "Interestingness in entrepreneurship research: international isomorphism and/or contextual heterogeneity?", Harirchi and Landström elaborate on what scholars in different regions and countries perceive as interesting in entrepreneurship research. They raise the question of whether entrepreneurship research demonstrates an increased "international isomorphism" on the one hand or, on the other hand, whether entrepreneurship research is characterized by a contextual heterogeneity. International isomorphism implies that interestingness is perceived as something more or less similar across regions. This could be explained by the observation that globalization has had significant consequences for research. Scholars gather together at international conferences, in workshops and in cross-regional collaborative projects. Journal articles and books are not only a common communication platform, but also an exponent of common standards and institutional norms in research around the world (Aldrich, 2000). The contrary view is that entrepreneurship may be seen as a phenomenon that differs due to the context. The perception of interestingness in research may reflect these contextual differences, implying that scholars in different regions will perceive interestingness in different ways.

Based on a unique database and web-based responses from 915 entrepreneurship scholars, Harirchi and Landström claim that there seem to be more similarities than differences in the perception of interestingness among entrepreneurship scholars. The analysis shows a mix of international isomorphism and contextual heterogeneity, but they find a strong trend towards increased convergence in the perception of interestingness in different parts 
in the world. The authors also provide several examples showing differences in topics assessed as interesting across regions. They argue that international isomorphism does not exclude a contextual heterogeneity in research, but that they complement each other. Harirchi and Landström find it important that our entrepreneurship research reflects existing contextual differences. To accomplish a stronger focus on contextual heterogeneity they formulate a number of suggestions: to have a stronger focus on reality, to increase the variety of scientific journals and to change the incentive systems at universities and business schools.

Chapter 3, "Breaking the rules to reach the top? The ethical dimension bound to the opportunity process", written by Gustav Hägg and Agnieszka Kurczewska, addresses the actual issue of how ethics plays an important role in understanding the entrepreneur throughout the entrepreneurial process. The authors' considerations are situated both in the context of an individualist entrepreneurial culture and neoliberal policy, and in the context of the sharing economy and the phenomenon of super entrepreneurs. They argue that the rise of the neoliberal governance but also the sharing economy and current focus on making arbitrage profits are posing many ethical challenges, which result in an increased interest in the entrepreneurial responsibility.

The theoretical foundation of the chapter is based on the discussion about the opportunity debate and ethics. The starting point for the deliberations is the observation that, so far, the discussion on the ethical dimension of entrepreneurship has mainly focused on the consequences of entrepreneurial actions. Seeing this approach as too limited, authors draw from normative ethics to conceptualize an opportunity process model that illustrates the entrepreneur as a moral agent who acts ethically from the early stage of the identification of entrepreneurial intention, through the entrepreneurial opportunity evaluation, to its exploitation. The model conceptualizes ethical responsibility in the entrepreneurial process building on the triple font theory of Mele (2012), which considers the two ethical views of deontology and teleology. The proposed model follows an individual agent's perspective and explains the complexity of the ethical responsibility faced by the entrepreneur, the importance of prudence in making ethical decisions, and the role of an entrepreneurial agent when engaging in the entrepreneurial opportunity process.

In the empirical part of the chapter, Hägg and Kurczewska apply a case study approach and pattern matching logic to investigate how the case of Airbnb follows the conceptual model. They analyse the ethical dimension of the opportunity process with an example of Airbnb in order to explicate the meaning of ethical responsibility for entrepreneurial practice in the opportunity process. One of the main conclusions drawn by the authors is that, by only seeing entrepreneurs through the consequences of their actions, we disregard the intentional part of the enactment process that takes place in the initial 
stage of discovering or creating opportunities. The authors also leave us with an interesting thought that a creation view on opportunities might provoke more issues related to norm-breaking behaviour that require a higher level of ethical responsibility when engaging in the entrepreneurial process as there is little to no historical data to rely on, whereas in a discovery view, at least in the initial stage, the entrepreneur has access to more historical data. However, the issue of consequences of entrepreneurial actions is of equal importance in both views.

The originality of Chapter 4, "Digital transition and CSR in French SMEs: managing paradoxes?", written by Sandrine Berger-Douce, is to provide an analysis that leads to answering the question of how to reconcile commitment to Corporate Social Responsibility (CSR) and digital transition in Small and Medium-Sized Enterprises (SMEs) through the theory of paradox in a specific cultural context of France. CSR is recognized as a guarantee of competitiveness for businesses, regardless of their size or their industry. The existence of multiple tensions is clearly inherent in the life of organizations. New tensions evolve due to globalization, rapid change and more intense competition. Societal challenges such as the commitment to CSR and more recently digital transformation still exacerbate this situation. The specificities of SMEs make these issues even more complex for these organizations.

The perspective of the paradox has developed since the 1980s based on the ability of organizations to respond simultaneously to competing demands (Smith and Lewis, 2011; McAdam et al., 2020). According to this perspective, tensions are certainly contradictory, but also interdependent (Smith et al., 2017). Beyond the decision to deploy management of these paradoxes is the question of organizational practices to be put in place to implement such strategies in companies. The literature on the paradoxes invites us to focus on longitudinal approaches (Schad et al., 2016). A single longitudinal case study (2014-2018) in an industrial French SME was conducted to provide some answers to this question. Berger-Douce opted for exploratory work using methods that allow for a richer understanding of context. Primary data were collected mainly through in-depth interviews with 12 internal interlocutors in the industrial SME from April to November 2018.

Getting involved in a digital transformation is by nature an innovative approach for French SMEs. Digital transformation requires enterprises to adapt to profound disruptive changes by using digital skills to create new business models, products, and services. In SMEs wishing to innovate in their business, leaders focus attention on Human Resources Management (HRM) practices to provide the levers of organizational transformation (Jamali et al., 2015). Managerial and HR practices are at the heart of the device as guarantors of the preservation of humanity in this digital transformation. The findings 
focus on HR management practices regarding required skills, recognition of the employees and redefinition of jobs.

In Chapter 5, "Effectuation elements of entrepreneurial networking under uncertainty", Taghvaee and Mauer contribute to the social dimension of context by investigating entrepreneurs' networking behaviours in a highly uncertain context. Entrepreneurial networking consists of strategies, activities, and capabilities by which entrepreneurs shape and maintain ties. The strategies to cope with uncertain situations is a significant determinant of success in entrepreneurial firms (McKelvie et al., 2011; Jiang and Tornikoski, 2019). By bridging with effectuation theory, the authors argue that entrepreneurs and other actors need to commit to resource allocation before making judgements under uncertainty. This networking behaviour is called pre-commitment and refers to strategy in which actors commit to allocating resources before having the ability to calculate the probability of success.

Taghvaee and Mauer aim to elaborate on effectuation elements of entrepreneurial networking by investigating entrepreneurs' network content, governance mechanisms, and structure. A multiple case study approach is adopted to consider specific elements of a pre-commitment approach to form and retain network ties. Within-case (historical) insights and between-case (comparative) insights are generated. The authors investigate what resources are exchanged, which governance mechanisms are taken, and what are the characteristics of network structure under the condition of relational and environmental uncertainty. Data from seven technologic new ventures that engage in networking activities in a highly uncertain context are analysed.

The chapter offers interesting findings regarding entrepreneurial networking. First, the results introduce two types of socio-cognitive resources of networking: shared idea knowledge and diffusion of responsibility. Second, affordable loss is conceptualized as a mechanism of partnership performance control through protecting strategic resources. Third, controlled trust is an informal mechanism driven by the trustee's means-based action and trustor's resource allocation based on affordable loss. New network ties with large firms provide new entrepreneurial firms with the access to resources and knowledge required to exploit opportunities. The authors generate insights on how to develop new opportunities in collaboration with other firms. They show also how to impede fatal failures in collaborations through restrictive mechanisms.

In Chapter 6, "Business model innovation and the Board in start-up companies: a dynamic capabilities perspective", Di Toma addresses how the Board interacts with business model innovation in the context of start-ups. In a dynamic competitive landscape influenced by phenomena such as digitalization, or social changes, business model innovation is a key source for gaining competitive advantage and performance (Casadesus-Masanell and Zhu 2013; Zott and Amit 2007). In start-up companies, innovating the business model 
can be especially relevant to adapt to competitive challenges. A decisive role is played by the Board, which is in charge of driving market success and the acquisition of the resources that will enable continuity and growth.

Dynamic capabilities have recently emerged as a promising perspective for understanding how firms may adapt and change to cope with environmental uncertainties and to build a competitive advantage (Teece et al., 1997). Dynamic capabilities allow firms to renew competencies and to strategically arrange and bundle organizational resources, skills, and routines as deemed appropriate by the firm's principal decision maker(s) to adapt to the evolving competitive conditions (Zahra et al., 2006, p. 924). A dynamic capability refers to a firm's capacity to purposefully create, extend, and modify its resource base (Helfat, 1997; Helfat and Peteraf, 2009) and requires the ability to manipulate substantive capabilities into higher order ones (Zahra et al., 2006). Resource transformation into appropriate capabilities may lead to gaining competitive advantage and superior performance.

Start-up companies are highly vulnerable organizational entities that often fail to survive beyond three years or to adapt to the new competitive challenges when they overcome their initial stage (Friedman et al., 2016; Zahra and Filatotchev, 2004). The development of dynamic capabilities in start-up companies and how they may result in a business model dynamic adaptation has been neglected by literature. Small entrepreneurial firms must often rely on the Board and especially the CEO to balance the lack of resources and organizational routines (Lubatkin et al. 2006; Zahra and Filatotchev 2004). However, how the Board and individual directors may act to develop dynamic capabilities enabling start-up companies to survive environmental uncertainties has been largely neglected in research. Based on the theories focusing the Board's role in the development of dynamic capabilities for business model innovation, this research investigates how and why the dialectic and interaction within the Board contributes to the development of distinctive know-how that fuels business model innovation.

The research is carried out by a single case study approach and investigates a start-up involved in the design of high tech innovative medical devices. Findings show how a new combinative capability is generated by dynamically shaping the ecosystem and managing relationships with the actors involved. Findings also cast some light on how the productive dialogue in conditions of relational engagement allows the development of a distinctive know-how that feeds the capabilities of business model innovation. The results are helpful to open the black box of the Board's behaviour and to understand how its strategic involvement is carried out.

In Chapter 7, “Accelerator networks as embedding mechanisms for internationalizing start-ups: a study in the Finnish edtech context", Kairikko and Dhaliwal aim to extend our knowledge about the role of accelerators for 
internationalizing edtech start-ups. On a theoretical level, this study draws on the concept of embeddedness and on international opportunities. Accelerator networks are considered mechanisms that enable start-ups to embed in the edtech sector during the parallel process of venture creation and international opportunity development. In the empirical part of the chapter, an in-depth, qualitative single case study was conducted within one spatial context (one industry in one country) to examine the phenomenon holistically. The research site was an accelerator in the emerging Finnish edtech sector. The extensive data consists of 46 interviews, observations, and documents. The interviews include entrepreneurs from start-ups, accelerator managers and representatives from accelerator networks and the edtech sector. The method of analysis was the constant comparative method, which has been used in previous studies to analyse entrepreneurial networks.

The chapter shows how accelerator networks enable start-ups to develop international opportunities. The findings determine that an accelerator may facilitate versatile local and international sector-specific partner networks, which contribute to the development of international opportunities. The findings emphasize the importance of co-creation and internationalization partners, which have received limited attention in previous studies. Furthermore, the findings display international opportunity development through formal and informal networks, tangible and intangible resources, and collaboration with open and pre-determined goals.

The study contributes to the emerging academic literature on accelerators by explaining the role of accelerator networks in the international opportunity development of start-ups. By addressing the particular features of start-ups and the newness of the ventures, the study enriches the discussion on international opportunities taking into account different dimensions of context such as the temporal, spatial and social dimensions.

In Chapter 8, "Career paths of female entrepreneurs in STEM - challenges and opportunities", Schnittker and Ettl investigate the career development and career paths of female entrepreneurs in the context of STEM fields. The STEM field (science, technology, engineering, and mathematics) is currently facing a huge skills shortage. This could provide women with great opportunities. However, both entrepreneurship and STEM are male-dominated fields, and STEM-sensitized women are already less likely to foster their careers or even to start businesses in STEM fields than are men.

This study is based on 30 semi-structured, qualitative interviews with female STEM entrepreneurs in different phases of their careers. Drawing on Krumboltz's (2009) Happenstance Learning Theory (HLT), which explains how and why people pursue their individual paths in life, and on the Stereotype Content Model (SCM) presented by Fiske et al. (2002) to explain the gender gap, authors discuss the career experiences and career-related decision-making 
processes of female STEM entrepreneurs and the role that stereotypes and perceptions play in this regard. Their aim is to derive recommendations and best practices at the academic, entrepreneurial, and intermediary levels for fostering female STEM entrepreneurship in the future.

The analysis of the sample shows that even women whose parents had a STEM business initially chose jobs in non-STEM fields. According to the interviewees, whether their parents themselves worked in STEM fields or were self-employed did not determine whether their daughter actively aimed to become a female STEM entrepreneur. In fact, the decisive factor seemed to be the woman's initial intrinsic interest in STEM, developed through hands-on experience. In most cases unplanned events significantly influence the career paths of female STEM entrepreneurs. Female STEM entrepreneurs frequently confront stereotypes concerning their positions and roles, although sometimes they can take advantage of these stereotypes. Being aware of multi-layered external perceptions, female STEM entrepreneurs perceive being female in male-dominated environments to be an opportunity, as they feel somewhat admired and respected for their successful career paths.

According to the findings, career entry seems to be the most critical milestone for a successful STEM-related career. Therefore, the authors support current endeavours to sensitize school-age girls to STEM-related professional paths to help them detect unconscious interests in those paths. Theoretical knowledge alone is insufficient, but it is crucial to give young women the opportunity to explore physical objects and to provide more hands-on experiences during school education to let children figure out their talents and interests in STEM fields in a hands-on manner.

While some earlier empirical research suggests that many immigrant entrepreneurs were "pushed" into lower-performing self-employment or necessity entrepreneurship (Clark and Drinkwater, 2000), recent empirical research often finds that immigrant entrepreneurs perform on average equally, if not better, than native-born entrepreneurs (Duhamel et al., 2017; Hart and Acs, 2011; Hart and Mickiewicz, 2016; Hunt, 2011; Neville et al. 2014). Human capital provides by far the most important explanation for the greater propensity and superior performance of immigrants in entrepreneurial activities relative to native-born. To explain the superior performance of immigrant entrepreneurs, Duhamel and St-Jean propose and test in Chapter 9, "Explaining the performance of immigrant entrepreneurship in market economies: empirical evidence of technology signaling", a novel hypothesis that many early-stage immigrant entrepreneurs have an incentive to competitively signal the quality of their business through credible novel technologies in order to overcome any information market barriers and market failures.

Duhamel and St-Jean selected from two years of the Global Entrepreneurship Monitor (GEM) a sample of 7,178 early-stage entrepreneurs in 28 developed 
market economies. The results suggest that the superior performance of early-stage immigrant entrepreneurs compared to their native-born peers can be explained, not only by the potentially superior entrepreneurial acumen of opportunity-driven immigrant entrepreneurs (Hunt 2011; Saxenian 2002; Vandor and Franke 2016), but also by the superior technologies adopted by necessity-driven immigrant entrepreneurs who may try to overcome information barriers and market failures. This evidence suggests that the latter may play a bigger role than had been acknowledged previously in the literature. Since economic inefficiencies can spill over from the labour market into the entrepreneurial business market when immigrants have to incur additional (sunk) signalling costs when they are pushed into entrepreneurial activities, Duhamel and St-Jean conclude that public policy should not only look at immigrant entrepreneurs as a cure to economic development but also as a potential symptom of unresolved discrimination in the labour market.

\section{OUTLOOK}

Contributors to this anthology have strongly argued that entrepreneurship as a phenomenon is highly context dependent. They have presented the results of the studies in a variety of contexts, describing their depth and meaning for both entrepreneurship research and practice. Entrepreneurship in the real world looks different in each region, in different cultural, political, and economic environments. Also, national and regional policies are focused on different aspects and refer to different socio-economic circumstances. Following all presented examples, it seems important that entrepreneurship research reflects contextual differences and addresses these differences with adequate attention for more complete understanding of the entrepreneurship phenomenon. Overall, this book offers new insights to our knowledge on the conditions of entrepreneurship and entrepreneurial behaviour in different contexts.

The chapters illustrate a rich variety of topics and research methods reflecting the multi-dimensional nature of context in entrepreneurship. As this collection of recent European entrepreneurship research indicates, a multitude of research approaches must be used, including qualitative methods in a longitudinal setting. All chapters discuss research questions hereby taken into account in one or more dimensions of context. The chapters warn us against too simplistic interpretations and too fast or even superficial conclusions of the research. Even if it is possible to empirically identify differences in entrepreneurial activities and behaviour between groups of individuals or between locations, there could be other dimensions of context that must be taken into consideration because, without them, an in-depth understanding is not possible. Collectively, the chapters illustrate that contextual heterogeneity is 
important to address in entrepreneurship research. The question of how context matters is, perhaps, the next in the evolution of our scientific knowledge.

\section{REFERENCES}

Aldrich, H.E. (2000), 'Learning together: National differences in entrepreneurship research', in D.L. Sexton and H. Landström (eds), The Blackwell Handbook of Entrepreneurship, Oxford: Blackwell, pp. 5-25.

Baker, T. and F. Welter (2018), 'Contextual entrepreneurship: An interdisciplinary perspective', Foundations and Trends ${ }^{\circledR}$ in Entrepreneurship, 14(4): 357-426

Blackburn, R., U. Hytti and F. Welter (2015), 'Introduction: Entrepreneurship, contextual, processs and gender differentations', in R. Blackburn, U. Hytti and F. Welter (eds), Context, Process and Gender in Entrepreneurship, Frontiers of European Entrepreneurship Research, Cheltenham, UK: Edward Elgar Publishing, pp. 1-5.

Casadesus-Masanell, R. and F. Zhu (2013), 'Business model innovation and competitive imi-tation: The case of sponsor-based BMs', Strategic Management Journal, 34 (4), 464-482.

Clark, K. and S. Drinkwater (2000), 'Pushed out or pulled in? Self-employment among ethnic minorities in England and Wales', Labour Economics, 7 (5), 603-628.

Duhamel, M., A.A. Houssou and É. St-Jean (2017), 'La contribution des immigrants aux aspirations entrepreneuriales de haute performance : Perspective empirique internationale du Global Entrepreneurship Monitor', Entrepreneuriat, Croissance et Compétitivité : Expériences comparées" Conference, Académie de l'entrepreneuriat et de l'innovation, December, Dakar, Senegal.

Fiske, S.T., A.J.C. Cuddy, P. Glick and J. Xu (2002), 'A model of (often mixed) stereotype content: Competence and warmth respectively follow from perceived status and competition', Journal of Personality and Social Psychology, 82 (6), 878-902.

Friedman, Y., A. Carmeli, and A. Tishler (2016), 'How CEOs and TMTs build adaptive capacity in small entrepreneurial firms', Journal of Management Studies, 53 (6), 996-1018.

Hart, D.M. and Z.J. Acs (2011), 'High-tech immigrant entrepreneurship in the United States', Economic Development Quarterly, 25 (2), 116-129.

Hart, M. and T. Mickiewicz (2016), Ambitious entrepreneurship and migration: A multilevel study across the local authorities in England and Wales. ERC Research Paper 47, Birmingham, UK: Entreprise Research Centre, University of Aston.

Helfat, C.E. (1997), 'Know-how and asset complementarity and dynamic capability accumulation: The case of R\&D', Strategic Management Journal, 18 (5), 339-360.

Helfat, C.E. and M.A. Peteraf (2009), 'Understanding dynamic capabilities: Progress along a developmental path', Strategic Organization, 7 (1), 91-102.

Hunt, J. (2011), 'Which immigrants are most innovative and entrepreneurial? Distinctions by entry visa', Journal of Labor Economics, 29 (3), 417-457.

Jamali, D., A. Dirani and I. Harwood (2015), 'Exploring HRM roles in CSR; the CSR-HRM co-creation model', Business Ethics: A European Review, 24, 125-143.

Jiang, Y. and E.T. Tornikoski (2019), 'Perceived uncertainty and behavioral logic: Temporality and unanticipated consequences in the new venture creation process', Journal of Business Venturing, 34 (1), 23-40.

Krumboltz, J.D. (2009), 'The Happenstance Learning Theory', Journal of Career Assessment, 17 (2), 135-54. 
Landström, H. and G. Harirchi (2019), “"That's interesting!” in entrepreneurship research', Journal of Small Business Management, 57 (S2), 507-529.

Landström, H. and F. Lohrke (eds) (2010), Historical foundations of entrepreneurial research, Cheltenham, UK and Northampton, MA, USA: Edward Elgar Publishing.

Lubatkin, M.H., Z. Simsek, Y. Ling and J.F. Veiga (2006), 'Ambidexterity and performance in small to medium-sized firms: The pivotal role of TMT behavioural integration', Journal of Management Studies, 32, 646-672.

McAdam, M., E. Clinton and C. Dibrell (2020), 'Navigation of the paradoxical landscape of the family business?', International Small Business Journal, 38 (3), 139-153.

McKelvie, A., Haynie, J. M., \& Gustavsson, V. (2011), 'Unpacking the uncertainty construct: Implications for entrepreneurial action', Journal of Business Venturing, 26 (3), 273-292.

Mele, D. (2012), Management ethics - placing ethics at the core of good management, London: Palgrave Macmillan.

Neville, F., B. Orser, A. Riding and O. Jung (2014), 'Do young firms owned by recent immi-grants outperform other young firms?', Journal of Business Venturing, 29 (1), $55-71$.

Porter, M. (1980), Competitive strategy, New York, NY: Free Press.

Saxenian, A. (2002), 'Silicon Valley's new immigrant high-growth entrepreneurs', Economic Development Quarterly, 16 (1), 20-31.

Schad, J., M.W. Lewis, S. Raisch and W.K. Smith (2016), 'Paradox research in management science: Looking back to move forward', The Academy of Management Annals, 10 (1), 5-64.

Smith, W.K. and M.W. Lewis (2011), 'Toward a theory of paradox: A dynamic equilibrium model of organizing', Academy of Management Review, 36 (2), 381-403.

Smith, W.K., M. Erez, S. Jarvenpaa, M.W. Lewis and P. Tracey (2017), 'Adding complexity to theories of paradox, tensions, dualities of innovation and change?', Organization Studies, 38 (3-4), 303-317.

Stuart, T.E. and O. Sorenson (2007), 'Strategic networks and entrepreneurial ventures', Strategic Entrepreneurship Journal, 1 (3-4), 211-227.

Teece, D.J., G. Pisano and A. Shuen (1997) 'Dynamic capabilities and strategic management', Strategic Management Journal, 18 (7), 509-533.

Ucbasaran, D., P. Westhead, and M. Wright (2001), 'The focus of entrepreneurial research: Contextual and process issues', Entrepreneurship: Theory \& Practice, 25 (4), 57.

Vandor, P. and N. Franke (2016), 'See Paris and ... found a business? The impact of cross-cultural experience on opportunity recognition capabilities', Journal of Business Venturing, 31 (4), 388-407.

Welter, F. (2011), 'Contextualizing entrepreneurship: Conceptual challenges and ways forward', Entrepreneurship Theory and Practice, 33 (1), 165-184.

Welter, F. and F. Lasch (2008), 'Entrepreneurship research in Europe: Taking stock and looking forward', Entrepreneurship Theory and Practice, 32 (2), 241-248.

Wright, M., P. Westhead and D. Ucbasaran (2007), 'Internationalisation by SMEs: A critique and policy implications', Regional Studies, 41 (7): 1013-1030.

Zahra, S.A. (2007), 'Contextualize theory building in entrepreneurship research', Journal of Business Venturing, 22, 443-452.

Zahra, S.A. and I. Filatotchev (2004), 'Governance of the entrepreneurial threshold firm: A knowledge-based perspective', Journal of Management Studies, 41 (5), 885-897. 
Zahra, S.A. and M. Wright (2011), 'Entrepreneurship's next act', Academy of Management Perspectives, 25 (4), 67-83.

Zahra, S.A., J. Sapienza and P. Davidsson (2006), 'Entrepreneurship and dynamic capabilities: A Review, model and research agenda', Journal of Management Studies, 43 (4), 917-955.

Zahra, S.A., M. Wright and S.G. Abdelgawad (2014), 'Contextualization and the advancement of entrepreneurship research', International Small Business Journal, 32 (3), 479-500.

Zott, C. and R. Amit (2007), 'Business model design and the performance of entrepreneurial firms', Organization Science, 18 (2), 181-199. 